\title{
Correction to: Imaging the Future of Smart Cities
}

\section{Correction to:}

Chapter 4 in: J. A. LugoSantiago, Leadership and Strategic Foresight in Smart Cities, https://doi.org/10.1007/978-3-030-49020-1_4

The original version of this chapter was inadvertently published with the wrong version of abstract. The chapter has now been updated with the correct version of the abstract given below:

Abstract Here is where we begin our exploration of the future. This chapter starts with setting the stage for a discussion about the future of our cities based on the influences that are controlling the narrative and the possible paths. Then, the chapter turns to how the exploration of different futures for our cities would look like, stressing the points of strategic intent, key processes, signposts, and futures on the horizon. This discussion is meant to change the leader's thinking paradigms and senses for discovering emerging futures on the horizon. That discussion is paramount to the understanding of how four city scenarios of the future were built.

The updated version of this chapter can be found at https://doi.org/10.1007/978-3-030-49020-1_4

(C) The Author(s) 2020 